Paidéia, 2004, 14 (28), 139 -152

\title{
DA FALA DO OUTRO AO TEXTO NEGOCIADO: DISCUSSÕES SOBRE A ENTREVISTA NA PESQUISA QUALITATIVA ${ }^{1}$
}

\author{
Márcia Tourinho Dantas Fraser ${ }^{2}$ \\ Sônia Maria Guedes Gondim \\ Universidade Federal da Bahia
}

\begin{abstract}
Resumo: O artigo discute a entrevista como técnica qualitativa de apreensão da percepção e da vivência pessoal das situações e eventos do mundo. A relação intersubjetiva, entrevistador e entrevistado, é de fundamental importância para permitir o acesso aos significados atribuídos pelas pessoas aos eventos do mundo, cujo produto é fruto das mútuas influências no processo de interação na entrevista. A primeira seção discute a abordagem qualitativa de pesquisa e aponta suas principais diferenças em relação à abordagem quantitativa, bem como as implicações da escolha teórico-metodológica para o uso da entrevista como técnica de pesquisa. A segunda seção caracteriza as entrevistas qualitativas quanto à estrutura, tipos, objetivos, papel dos participantes e discute ainda critérios de seleção dos entrevistados, representatividade, validade e fidedignidade das interpretações dos resultados. A última seção apresenta algumas considerações sobre os limites e possibilidades de uso da técnica.
\end{abstract}

Palavras-chave: entrevista; abordagem qualitativa; técnicas de pesquisa.

\section{FROM THE SPEECH OF THE OTHER TO THE NEGOTIATED TEXT: DISCUSSIONS ABOUT THE INTERVIEW IN THE QUALITATIVE RESEARCH}

\begin{abstract}
The article discusses the interview as a qualitative technique in the apprehension of perception and personal experience of world situations and events. The intersubjective relation, interviewer and interviewee, is of fundamental importance for allowing the access to the signs attributed by persons to the world events, as such product is the result of mutual influences in the interacting process in interview. The first section discusses the qualitative approach of the research and points the main differences towards the quantitative approach, as well as the theorical-methodological implications for using the interview as a technique for research. The second characterizes the qualitative interviews within the structure, types, participants role, and also discusses criteria in selecting the interviewees, representativity, validity, and trustworthiness in the results of the interpretations. The last section presents some considerations about the limits and possibilities in using the technique.
\end{abstract}

Key-words: interview; qualitative approaches; research techiniques.

A entrevista é considerada uma modalidade de interação entre duas ou mais pessoas. Trata-se de uma conversação dirigida a um propósito definido que não é a satisfação da conversação em si, pois esta última é mantida pelo próprio prazer de estabelecer contato sem ter o objetivo final de trocar informações, ou seja, diminuir as incertezas acerca do que o interlocutor diz (Haguete, 2001; Lodi, 1991). Dito

\footnotetext{
${ }^{1}$ Artigo recebido para publicação em 03/11/2003; aceito em 08/05/2004. ${ }^{2}$ Endereço para correspondência: Rua Aristides Novis, 105, Edifício Bosque Suisso, Apto. 1102B, Federação Salvador, Bahia, Cep 40210630, E-mail: mtd-fraser@uol.com.br
}

de outro modo, a entrevista é uma forma de interação social que valoriza o uso da palavra, símbolo e signo privilegiados das relações humanas, por meio da qual os atores sociais constroem e procuram dar sentido à realidade que os cerca (Flick, 2002; Jovechlovitch \& Bauer, 2002).

O uso desta técnica parece estar localizado no campo da medicina, dado o interesse nesta área em se obter informações pormenorizadas do paciente para dar subsídios ao diagnóstico das doenças. Mais tarde, sua aplicação foi estendida para outros domí- 


\section{Márcia Tourinho Dantas Fraser}

nios, com objetivos diversos conforme cada área de aplicação. Atualmente é empregada principalmente na clínica em geral, na seleção de pessoas e na investigação científica. Na clínica, a entrevista constitui uma técnica fundamental não só para o diagnóstico, como também para a intervenção terapêutica. Na seleção de pessoas, o foco é na avaliação comparativa do candidato para fundamentar prognósticos de desempenho futuro no trabalho, e, por último, na pesquisa científica, a entrevista é utilizada principalmente como fonte de coleta de dados.

Embora se reconheça que as abordagens e as discussões que circunscrevem o uso da entrevista sejam amplas, o objetivo deste artigo é o de discutir algumas de suas vantagens como técnica de pesquisa na perspectiva qualitativa. Uma delas é a de favorecer a relação intersubjetiva do entrevistador com o entrevistado, e, por meio das trocas verbais e nãoverbais que se estabelecem neste contexto de interação, permitir uma melhor compreensão dos significados, dos valores e das opiniões dos atores sociais a respeito de situações e vivências pessoais. Outra vantagem é a flexibilização na condução do processo de pesquisa e na avaliação de seus resultados, visto que o entrevistado tem um papel ativo na construção da interpretação do pesquisador. Esta seria uma modalidade de triangulação (confiabilidade), pois, ao invés de o pesquisador sustentar suas conclusões apenas na interpretação que faz do que o entrevistado diz, ele concede a este último a oportunidade de legitimá-la. Este é um dos aspectos que caracteriza o produto da entrevista qualitativa como um texto negociado.

Acredita-se que a entrevista como técnica de pesquisa social associada às observações etnográficas tenha sido usada inicialmente por Booth, em 1886, em estudo sobre as condições sociais e econômicas dos habitantes de Londres. A entrevista como técnica de investigação científica foi gradativamente difundida nas pesquisas qualitativas e nas pesquisas quantitativas (Fontana \& Frey, 1994). As pesquisas de opinião, de tradição quantitativa, por exemplo, também passaram a fazer uso mais sistemático de entrevistas, impulsionadas, principalmente, pela criação do Instituto Americano de Opinião Pública por Gallup, em 1935, e pelos estudos das atitudes na psicologia social de Thomas e Znaniecki (Fontana
\& Frey, 2000).

Em princípio, as variadas abordagens de pesquisa adotam pontos de vistas diferentes sobre a prática, orientam-se por pressupostos ontológicos e epistemológicos diversos e focalizam distintos aspectos na sua investigação (Kemmis \& Mctaggart, 2000; Rey, 2002). A sua diversidade está alicerçada em divergências metodológicas que repercutem no uso da própria técnica de entrevista, na sua estrutura, na definição de seus objetivos, no papel do entrevistador e do entrevistado, e nas formas de validação de seus resultados.

Compartilha-se, neste artigo, a opinião de que a multiplicidade de abordagens de pesquisa pode ser enriquecedora para o conhecimento científico (Hollis, 2002), entendendo-se que a questão central deva localizar-se nas opções teórico-metodológicas que repercutem na decisão dos níveis de análise da ação social circunscritos a um paradigma ${ }^{3}$.

A entrevista na pesquisa qualitativa, ao privilegiar a fala dos atores sociais, permite atingir um nível de compreensão da realidade humana que se torna acessível por meio de discursos, sendo apropriada para investigações cujo objetivo é conhecer como as pessoas percebem o mundo. Em outras palavras, a forma específica de conversação que se estabelece em uma entrevista para fins de pesquisa favorece o acesso direto ou indireto às opiniões, às crenças, aos valores e aos significados que as pessoas atribuem a si, aos outros e ao mundo circundante. Deste modo, a entrevista dá voz ao interlocutor para que ele fale do que está acessível a sua mente no momento da interação com o entrevistador e em um processo de influência mútua produz um discurso compartilhado pelos dois atores: pesquisador e participante. Ao contrário, quando o foco de investigação é o comportamento humano, ou seja, a forma como as pessoas agem no cotidiano e não somente falam sobre ele, existem outras técnicas, tais como a observação participante e a observação sistemática que permitem melhor atender a estes objetivos.

A observação participante é uma modalidade

\footnotetext{
${ }^{3}$ Masterman (1979) identifica três principais sentidos da noção de paradigma na obra de Kuhn: o metafísico, que consiste em um princípio organizador da percepção da realidade, o sociológico, que é uma forma padronizada compartilhada pelos cientistas de conceber o que é ciência e, por último, o metodológico, que funciona como um aparato técnico para orientar o fazer científico do pesquisador.
} 
de observação bastante empregada em estudos de natureza antropológica e sociológica e se distingue da observação sistemática pelo fato de esta última defender o distanciamento entre o observador e o fenômeno a ser observado, assim como a objetividade da observação, garantida pela adoção de procedimentos rigorosos de registros. De maneira distinta, a observação participante parte da premissa de que a apreensão de um contexto social específico só pode ser concretizada se o observador puder imergir e se tornar um membro do grupo social investigado. Só então, poderá compreender a relação entre o cotidiano e os significados atribuídos por este grupo.

Toda técnica de pesquisa tem alcances e limites demarcados e, para que seus resultados sejam confiáveis, são necessários, além da coerência com o paradigma escolhido e com o objeto de estudo, o conhecimento e o domínio da técnica pelo pesquisador, o que é perfeitamente aplicável no caso da entrevista.

O presente texto foi redigido com o objetivo de discorrer sobre alguns aspectos metodológicos do uso de entrevista na perspectiva qualitativa e para tal está dividido em três seções: a primeira delas circunscreve a abordagem qualitativa de pesquisa nas ciências sociais e destaca as suas principais diferenças em relação à abordagem quantitativa. A segunda seção define e caracteriza metodologicamente as entrevistas qualitativas no que se refere a sua estrutura, aos seus objetivos e ao papel dos participantes, assim como discute os critérios de seleção dos entrevistados, a representatividade da amostra e as modalidades de entrevistas, individual e grupal. A finalização é feita com comentários sobre o uso e os limites desta técnica.

\section{A abordagem qualitativa de pesquisa}

A abordagem qualitativa ou idiográfica surge como contraponto à abordagem monotética que defende a quantificação e o controle das variáveis para que o conhecimento objetivo do mundo seja alcançado. O fundamento da abordagem nomotética está na crença de que o modelo das ciências naturais é pertinente para as ciências sociais e, em sendo assim, estas deveriam aderir à proposição de que as leis gerais que regem os fenômenos do universo são necessárias e constantes. Caberia às ciências sociais, então, descobrir as leis gerais do comportamento e das ações humanas por meio da adoção dos procedimentos metodológicos das ciências naturais.

$\mathrm{O}$ ponto de vista da abordagem qualitativa e compreensiva, no entanto, é o de que os modelos científicos das duas ciências são diferenciados, dada a natureza distinta de seus objetos. A ação humana é intencional e reflexiva, cujo significado é apreendido a partir das razões e motivos dos atores sociais inseridos no contexto da ocorrência do fenômeno, o que não acontece com os objetos físicos, foco de análise das ciências naturais. Conhecer as razões e os motivos que dão sentido às aspirações, às crenças, aos valores e às atitudes dos homens em suas interações sociais é o mais importante para as ciências sociais. Dilthey, autor de abordagem compreensiva, defendeu o método histórico-antropológico ao afirmar que os fenômenos humanos são apreendidos ao se integrar a representação, o sentimento e a vontade e inseri-los em uma perspectiva histórica (Amaral, 1987). Weber, outro representante desta abordagem, diferenciou a compreensão direta (objetiva) da compreensão indireta (subjetiva) e influenciou significativamente a fenomenologia do mundo social elaborada por Schütz (1972) ${ }^{4}$. Em resumo, a abordagem qualitativa ou idiográfica parte da premissa de que a ação humana tem sempre um significado (subjetivo ou intersubjetivo) que não pode ser apreendido somente do ponto de vista quantitativo e objetivo (aqui entendido como independente do percebedor e do contexto da percepção). O significado subjetivo diz respeito ao que se passa na mente consciente ou inconsciente da pessoa (individualismo metodológico - o nível de análise é a pessoa) e o significado intersubjetivo se refere ao conjunto de regras e normas que favorecem o compartilhamento

\footnotetext{
${ }^{4}$ A rigor, embora não seja objeto de consideração adicional neste artigo, a abordagem compreensiva de Weber inclui duas dimensões de significado: subjetivo e objetivo. O subjetivo diz respeito àquele significado que está atrelado à intencionalidade do agente dirigida a um futuro "motivos para”, e o objetivo se refere àquele significado que pode ser apreendido por meio da observação e da análise de fatos passados "motivos porque” . Exemplo: pode-se compreender que duas amigas, Mariana e Flora, tenham rompido seus laços de amizade "porque" Mariana foi extremamente indelicada com Flora que a havia acusado de desonestidade. A intenção de Mariana (motivo para) foi causar constrangimento e ferir a amiga, deixando em evidência sua mágoa (Schütz, 1972).
} 


\section{Márcia Tourinho Dantas Fraser}

de crenças por grupos de pessoas inseridas em determinado contexto sóciocultural (holismo metodológico - o nível de análise é a estrutura e os sistemas).

Se o pesquisador concorda com os princípios da abordagem nomotética seus esforços de investigação empírica, incluindo a escolha e uso de técnicas, serão congruentes com a crença de que os fenômenos psicológicos devem ser estudados do mesmo modo que os fenômenos físicos, com repercussões para os procedimentos de pesquisa a serem adotados: padronização, controle de variáveis e grau de distanciamento do pesquisador de seu objeto de estudo. A entrevista, neste caso, obedecerá a um roteiro estruturado, os entrevistadores se submeterão a um treinamento para neutralizar as diferenças individuais e a análise dos resultados estará focada apenas nas respostas do entrevistado, ignorando que elas são, em grande parte, produto da interação que se estabelece entre entrevistador e entrevistado.

A diferença entre qualitativo e quantitativo encontra apoio na escolha de abordagens que são sustentadas por pressupostos filosóficos distintos. Mais afinados com a abordagem nomotética encontram-se o positivismo e o pós-positivismo e, mais identificados com a abordagem idiográfica destacamse a teoria crítica social, o construtivismo e o participacionismo. Os dois primeiros aportes teóricos defendem o ponto de vista de que a realidade é externa ao sujeito e passível de ser apreendida de modo objetivo e invariável; e os três subseqüentes o de que a realidade é dinâmica, histórica e socialmente construída pelo sujeito na interação subjetivo-objetivo (Alves-Mazzotti \& Gewandsznajder, 1994; Gondim, 2002a; Lincoln \& Guba, 2000; Radnitzky, 1970; Smith, Harré \& Langenhove, 1995).

Para os positivistas, a questão central é a objetividade. A análise social para ser objetiva (independente do sujeito percebedor) necessita ser quantificada ou mensurada a partir de instrumentos padronizados que assegurem a neutralidade e que possibilitem fazer generalizações com precisão, em conformidade com o modelo das ciências naturais. As ciências sociais, por sua vez, mesmo que lidem com um objeto de estudo que, distintamente de um objeto físico e passivo, reage diante de seu pesquisador, deveriam seguir este mesmo modelo se o seu interesse for o de alcançar um status próximo ao das ciências naturais, o que de modo algum é objeto de consenso entre os teóricos das ciências sociais (Minayo, M.C. de S., Deslandes, S.F.; Neto, O.C. \& Gomes, R. (2000).

A tradição idiográfica, em contrapartida, defende o ponto de vista de que as ciências sociais têm como objetivo central a compreensão da realidade humana vivida socialmente. O essencial não é quantificar e mensurar e sim captar os significados. O que se busca não é explicar a relação antecedente e conseqüente (nexos causais) e sim compreender uma realidade particular na sua complexidade (influência mútua dos atores sociais na construção de sua realidade). Sendo assim, as ciências sociais não deveriam aproximar-se do modelo das ciências naturais, pois tal modelo não atenderia às necessidades e especificidades de seu objeto de estudo.

Esta dicotomia entre qualitativo e quantitativo é palco de inúmeras controvérsias teóricas que procuram definir qual é o melhor método de pesquisa e quais os critérios de validade científica. O positivismo é criticado, principalmente, por reduzir o conhecimento da realidade social àquilo que pode ser observado, mensurado e quantificado; sobre a abordagem compreensiva, recaem críticas ao subjetivismo do pesquisador no processo de investigação e a ausência de controle na coleta de dados e na sua interpretação (Minayo, \& Cols., 2000).

A crise das abordagens concorrentes teve um de seus pontos altos na década de 60 , do século passado, influenciada também pelos questionamentos de Kuhn (1975) sobre a objetividade e a racionalidade da ciência, e pelas críticas da Escola da Teoria Crítica Social (denominada por alguns de Escola de Frankfurt) sobre aspectos ideológicos e atitudes da ciência dominante. A crítica mais recorrente ao positivismo é a de que este considera o conhecimento científico como uma fotografia fiel, objetiva e neutra da realidade (Alves-Mazzotti \& Gewandsznajder, 1994).

Entre os oponentes do positivismo, há aqueles que buscam posição conciliatória, como, por exemplo, Kemmis e Mctaggart (2000), para quem o debate constante entre as abordagens quantitativas e qualitativas sobre a validade e a adequação de suas técnicas é um equívoco, pois não existe abordagem capaz de garantir a verdade sobre um objeto. As di- 
ferentes tradições teóricas focalizam distintos aspectos nas suas investigações - as perspectivas objetiva e subjetiva, o enfoque social, grupal ou individual , assim como diversificados métodos e técnicas de investigação são utilizados em função dos aspectos práticos que se pretende enfatizar.

A discussão apresentada nesta seção teve como objetivo considerar criticamente alguns aspectos que permitissem entender que a entrevista pode ser uma técnica utilizada tanto em pesquisas qualitativas quanto quantitativas, a depender da abordagem metodológica escolhida pelo pesquisador. Caso ele opte pela abordagem quantitativa e nomotética, os seus esforços serão dirigidos para garantir a neutralidade e a objetividade das informações obtidas, principalmente pela padronização das perguntas e da postura do entrevistador, assim como pela escolha aleatória ou estratificada dos entrevistados. Se, ao contrário, a escolha for pela abordagem qualitativa, os esforços serão dirigidos: 1) para garantir a representatividade dos significados, passível de ser obtida ao entrevistar aqueles que conhecem e compreendem profundamente a realidade a ser estudada, 2) para permitir que o entrevistado sinta-se mais livre para construir seu discurso e apresentar seu ponto de vista, o que faz com que o roteiro seja o mais flexível possível, e, por último, 3) para submeter as interpretações do pesquisador à avaliação crítica dos próprios participantes da pesquisa (legitimidade).

Enfim, esta breve explicitação pretendeu discorrer sobre o paradigma de pesquisa qualitativo e as principais diferenças entre essa abordagem e a perspectiva quantitativa, já que essas diferenças repercutem, também, no uso da própria técnica. Agora o foco recairá no uso da técnica de entrevista.

\section{A técnica da entrevista}

Esta seção caracteriza a técnica da entrevista e focaliza suas especificidades e sua utilização nas investigações qualitativas. A seção está dividida em quatro partes, a saber: 1) estrutura e objetivos, 2) o papel do entrevistador e dos entrevistados, 3) seleção dos entrevistados e representatividade da amostra e 4) entrevistas individuais e grupais.

\section{Estrutura e objetivos}

Há duas modalidades mais gerais de entrevista: a face a face e a mediada. A primeira se refere àquela modalidade em que entrevistador e entrevistado se encontram um diante do outro e estão sujeitos às influências verbais (o que é dito ou perguntado), às não-verbais (comunicação cronêmica - pausas e silêncios -, cinésica - movimentos corporais -, e paralinguística - volume e tom de voz), e às decorrentes da visualização das reações faciais do interlocutor. A segunda modalidade inclui as entrevistas feitas por telefone, por computador e por questionários, que também estão sujeitas às mesmas influências verbais e não-verbais, mas de modo diferenciado, em especial quando não permitem a visualização das reações faciais do interlocutor.

Em relação a sua estruturação, por sua vez, as entrevistas podem ser estruturadas, semi-estruturadas ou não estruturadas. As entrevistas estruturadas ou fechadas são utilizadas, freqüentemente, em pesquisas quantitativas e experimentais. A preocupação é com o ajuste do roteiro às hipóteses previamente definidas, a padronização da apresentação de perguntas e a limitação das opções de respostas para facilitar o planejamento das condições experimentais e do tratamento estatístico dos dados.

Em outras palavras, esta modalidade de entrevista se caracteriza por uma estruturação rígida do roteiro e oferece pouco espaço para a fala espontânea do entrevistado. $\mathrm{O}$ roteiro da entrevista é préelaborado e testado, assim como as questões obedecem a uma seqüência rigorosa com pouca flexibilidade para a formulação das perguntas e para o subseqüente aproveitamento de comentários adicionais dos entrevistados. A posição esperada do entrevistador é a mais neutra possível, devendo evitar esboçar qualquer opinião que possa sugerir a sua visão pessoal e, diante de qualquer dúvida do entrevistado a respeito do conteúdo da pergunta formulada, o entrevistador deve apenas repetir o enunciado, sem oferecer explicações complementares que não tenham sido previstas pelo roteiro inicial. Desta forma, os procedimentos se uniformizam para todos os entrevistados e entrevistadores (Fontana \& Frey, 2000).

As entrevistas estruturadas, em grande parte, se fundamentam na existência de um conhecimento exterior que pode ser apreendido pelo pesquisador, 


\section{Márcia Tourinho Dantas Fraser}

desde que todos os procedimentos metodológicos recomendados tenham sido seguidos. Elas podem apoiar-se em um questionário, com perguntas e respostas de múltipla escolha, ou em um roteiro fixo contendo perguntas objetivas que permitam respostas abertas a serem posteriormente submetidas a técnicas de análise de conteúdo, com ênfase quantitativa (Bardin, 1977; Smith, 2000). O excesso de estruturação, entretanto, inibe a livre manifestação da opinião do entrevistado, o que é fundamental para a compreensão de sistemas de valores e significados de um grupo social. Por exemplo, uma entrevista estruturada e apoiada em questionário de múltipla escolha sobre nutrição poderia conter uma pergunta do seguinte tipo:

O que você mais valoriza na alimentação?

a) nutrientes do alimento

b) sabor do alimento

c) quantidade de alimento disponível.

Se o entrevistado A escolher a letra c, o entrevistador poderá inferir que a quantidade de alimento tem mais valor para o entrevistado do que os outros fatores (sabor e nutrientes), mas esta informação será insuficiente para compreender por que o entrevistado dá importância mais a este aspecto que aos demais, ou seja, quais as motivações e os valores que estariam sustentando a escolha do entrevistado.

Uma pesquisa qualitativa sobre o mesmo tema poderia mais facilmente optar por uma estrutura de entrevista que privilegiasse questões abertas, tais como: O que você valoriza na sua alimentação? Este tipo de questão permitiria ao entrevistado, por exemplo, dizer que valoriza uma mesa farta porque é descendente de italiano e isto lhe faz lembrar a sua infância e os almoços dominicais na casa da avó, uma típica mama italiana que valorizava os encontros familiares e via na diversidade e quantidade disponível de alimentação uma maneira de demonstrar felicidade com a chegada dos convidados.

Uma resposta desse tipo oferece informações ricas sobre a importância do processo de socialização na formação de hábitos alimentares e os aspectos culturais envolvidos na nutrição, que poderiam ser ignorados em uma entrevista fechada. Em outras palavras, as opções nutrientes do alimento, sabor do alimento e quantidade de alimento disponível estão restritas ao seu valor individual para a pessoa e podem levar o pesquisador a concluir apenas que 0 entrevistado A se preocupa com a quantidade e não com a qualidade, sendo que o que está em jogo é o fato de que a quantidade de alimento disponível na mesa é fundamental para demonstrar a alegria em receber os familiares, não importando o consumo integral do alimento disponível.

Em geral, na pesquisa quantitativa ou experimental, o enfoque que se pretende dar ao tema já é definido desde o planejamento do roteiro da entrevista (hipóteses a serem testadas), determinando o número e o conteúdo das perguntas. No caso de pesquisas qualitativas, o enfoque é mais vago (tema mais amplo) e é comum que ele se defina no próprio processo da entrevista, ou seja, à medida que o entrevistado vai expressando suas opiniões e significados, novos aspectos sobre o tema vão emergindo e o entrevistador pode redefinir seu roteiro para obter informações que permitam ampliar sua compreensão do tema.

As entrevistas mais comumente utilizadas nas pesquisas qualitativas são as semi-estruturadas e as não-estruturadas. A opção por uma delas está relacionada com o nível de diretividade que o pesquisador pretende seguir, variando desde a entrevista na qual o entrevistador introduz o tema da pesquisa e deixa o entrevistado livre para discorrer sobre o mesmo, fazendo apenas interferências pontuais (por exemplo: história oral), até a entrevista um pouco mais estruturada, que segue um roteiro de tópicos ou perguntas gerais (Bartholomew, Henderson \& Márcia, 2000).

Talvez a forma mais representativa de entrevista não estruturada seja a da clínica psicoterápica, como é o caso da entrevista psicanalítica. Neste contexto, é o paciente (entrevistado) que solicita a entrevista, e sua fala e seu discurso dirigem todo o processo. Ao psicanalista (entrevistador), cabe oferecer uma "escuta" diferenciada, restringindo suas intervenções ao mínimo, apenas para facilitar a livre associação do paciente e possibilitar que o processo analítico aconteça.

Se uma pessoa marca uma entrevista inicial com um psicanalista porque se sente deprimida e pede para que ele lhe indique um caminho por onde começar ou lhe diga o que é o mais importante falar (não é 
incomum na prática clínica o paciente perguntar o que interessa ao analista saber), a orientação do profissional será no sentido de estimular que o paciente fale livremente, evitando fazer uma anamnese ou definir tópicos, pois, na clínica psicanalítica, o que a pessoa prioriza para falar e a forma particular como organiza o seu próprio discurso são importantes dados clínicos.

A entrevista não estruturada na pesquisa qualitativa possui características diferentes da entrevista clínica. A rigor, considera-se que a entrevista aberta e dirigida inteiramente pelo próprio entrevistado seja difícil de ser realizada na pesquisa científica, pois, uma investigação desta natureza, mesmo que não tenha definido uma hipótese a ser colocada à prova, é dirigida a um objeto específico (problema de pesquisa) de investigação escolhido pelo pesquisador, o que, a princípio, impõe um limite à liberdade da fala do entrevistado.

Apesar de reconhecer essa limitação, a entrevista em pesquisa qualitativa procura ampliar o papel do entrevistado ao fazer com o que o pesquisador mantenha uma postura de abertura no processo de interação, evitando restringir-se às perguntas pré-definidas, de forma que a palavra do entrevistado possa encontrar brechas para sua expressão. É prática comum a elaboração de um roteiro apresentado sob a forma de tópicos (tópico-guia) que oriente a condução da entrevista, mas que de modo algum impeça o aprofundamento de aspectos que possam ser relevantes ao entendimento do objeto ou do tema em estudo. Para a elaboração dos tópicos, é importante que o pesquisador avalie seus interesses de investigação e proceda a uma crítica da literatura sobre o tema (Gaskell, 2002). Além de ser um instrumento orientador para a entrevista, o tópico guia pode ser útil para a elaboração e antecipação de categorias de análise dos resultados.

Um outro aspecto que justifica a defesa da não estruturação ou semi-estruturação da entrevista na pesquisa qualitativa é que esta abordagem almeja compreender uma realidade particular e assume um forte compromisso com a transformação social, por meio da auto-reflexão e da ação emancipatória que pretende desencadear nos próprios participantes da pesquisa. Para os defensores da abordagem qualitativa, a realidade humana é construída no processo de inserção do indivíduo em um contexto social particular e, em decorrência, os participantes são vistos como pessoas que constroem seus discursos e baseiam suas ações nos significados derivados dos processos de comunicação com os outros, com quem compartilham opiniões, crenças e valores. Deste modo o poder de ação e transformação das pessoas pode ser ampliado ao ser propiciado a cada uma delas refletir sobre suas próprias concepções, crenças e ações (Alves-Mazzotti \& Gewandsznajder, 1994; Gergen \& Gergen, 2000; Gondim, 2002a).

A entrevista qualitativa tem a finalidade de atender aos objetivos da pesquisa, que podem ser diversos. Ela pode ser utilizada como a única técnica de pesquisa, como técnica preliminar ou ainda associada a outras técnicas. No primeiro caso, o propósito da pesquisa pode ser apenas o de compreender os significados e as vivências dos entrevistados no que tange a determinadas situações e eventos. Por exemplo, uma pesquisa define como objetivo central conhecer a representação social de um grupo de idosos de um asilo $\mathrm{X}$ sobre o envelhecimento e elege a entrevista semi-estruturada como sua principal fonte de dados. Ao pesquisador deste estudo, interessa compreender como esses idosos percebem e vivenciam seu próprio envelhecimento. Nada impede, entretanto, que os resultados sejam utilizados para orientar o trabalho de profissionais do próprio asilo, para oferecer subsídios para o desenvolvimento de políticas sociais mais amplas, bem como para servir de referência à formulação de hipóteses e de teorias que poderão vir a ser testadas no futuro.

O uso da entrevista qualitativa como técnica preliminar pode ter como objetivo explorar informações ou dados que permitam a construção de outros instrumentos de pesquisa. Uma investigação sobre o significado do lazer para o público jovem brasileiro, por exemplo, pode ser conduzida para subsidiar a elaboração de uma escala. Na etapa inicial da pesquisa, poderiam ser feitas entrevistas qualitativas para conhecer as opiniões gerais de jovens brasileiros (variando gênero, classe social, etnia, nível de escolaridade e bairro de moradia) a respeito do lazer e, a partir daí, proceder à categorização e à análise das respostas e comentários, de modo que informações significativas sobre o assunto fossem reunidas para compor a escala sobre o significado do lazer 


\section{Márcia Tourinho Dantas Fraser}

e delimitar seus componentes ou fatores. Findo isto o pesquisador validaria o instrumento por meio da aplicação de questionários a uma amostra aleatória da população brasileira.

Finalmente, a associação de entrevista qualitativa com outras técnicas de pesquisa é muito freqüente nos estudos etnográficos, que, por exemplo, costumam utilizá-la com as técnicas de observação. Isto se revela útil porque, ao se propor estudar características culturais de determinada comunidade, o pesquisador pode estar interessado em conhecer as crenças, os valores e as opiniões das pessoas, e, também, em perceber de que modo estes valores e crenças se expressam no cotidiano das pessoas, ou seja, na sua conduta ou comportamento diários, o que torna pertinente associar entrevistas à observação participante.

Em síntese, foram destacados, nesta parte da seção, as modalidades, a variabilidade de estruturação e os objetivos da entrevista. No próximo item, será discutido o papel do entrevistador e do entrevistado na interação.

\section{O papel do entrevistador e do entrevistado: da fala do outro ao texto negociado}

Um ponto fundamental a ser considerado é o papel dos participantes nas entrevistas qualitativas. Mais de uma vez, foi mencionado neste artigo que a entrevista é essencialmente uma comunicação verbal e consiste em um tipo de interação com objetivos específicos, que visa a compreensão de como os sujeitos percebem e vivenciam determinada situação ou evento que está sendo focalizado. Embora se reconheça que os papéis do pesquisador e do pesquisado sejam diferenciados, a crença é a de que somente se o entrevistador mantiver uma relação de maior proximidade com o entrevistado é que a compreensão do mundo pela sua perspectiva se tornará acessível.

Na pesquisa experimental ou quantitativa, a preocupação é com a preservação da neutralidade da influência do pesquisador no que o entrevistado irá dizer, o que repercute na acentuação da demarcação de seus papéis. O papel do entrevistador é o de dirigir o processo e formular perguntas de modo padronizado, enquanto ao entrevistado compete responder de maneira objetiva, o que irá facilitar a categorização de respostas e a generalização dos resultados para a população investigada.

Na abordagem qualitativa, entretanto, o que se pretende, além de conhecer as opiniões das pessoas sobre determinado tema, é entender as motivações, os significados e os valores que sustentam as opiniões e as visões de mundo. Em outras palavras é dar voz ao outro e compreender de que perspectiva ele fala. Para atingir este objetivo, o entrevistador assume um papel menos diretivo para favorecer o diálogo mais aberto com o entrevistado e fazer emergir novos aspectos significativos sobre o tema. A relação intersubjetiva, então, é condição para o aprofundamento, visto que a abordagem qualitativa advoga que a realidade social não tem existência objetiva independente dos atores sociais, mas ao contrário, é construída nos processos de interações sociais. Dito de outro modo, mesmo que se reconheça, por exemplo, que os livros sobre a mesa continuam a existir objetivamente independente de se estar olhando fixamente para eles, só adquirem sentido à medida que se encontram representados na mente de cada um e carregam consigo um conjunto de significados a eles atribuídos nas interações sociais passíveis de serem continuamente redefinidos. $\mathrm{Na}$ mente de cada pessoa, o livro pode ser representado por descrições gerais - os livros são formados por um conjunto de folhas impressas e encadernadas que contém registros verbais; mas igualmente por avaliações - os livros contribuem para ajudar na difusão do conhecimento e oferecem informações para o crescimento humano.

Ao adotar essa mesma perspectiva, Fontana e Frey (2000) consideram que a entrevista qualitativa é um "texto negociado" resultante de um processo interativo e cooperativo que envolve tanto o entrevistado como o entrevistador na produção do conhecimento. A expressão "texto negociado" deixa transparecer que os resultados de pesquisas que se apóiam em entrevistas semi-estruturadas ou abertas são decorrentes de uma produção desencadeada pelo processo ativo de trocas verbais e não verbais entre o participante e o pesquisador. Se de um lado, os pesquisadores de abordagem experimental e quantitativa investem em pesquisas para orientar a adoção de procedimentos metodológicos que venham a minimizar os vieses e a influência do pesquisador no processo de coleta de dados (Darley \& Gross, 
2000), de outro, os pesquisadores qualitativos afirmam que não há como assegurar tal distanciamento, visto sermos seres sociais ativos e estarmos continuamente interferindo nos acontecimentos a nossa volta e sendo influenciados por eles.

A adesão à crença de que a realidade é apreendida intersubjetivamente constitui, para os defensores da abordagem qualitativa, uma das razões que justificam a escolha pela técnica de entrevista semiestruturada ou aberta em detrimento da entrevista estruturada. É justamente pela adesão a esta crença que muitas críticas são dirigidas a estas modalidades de entrevista, em particular pela ausência de objetividade, que permite que diferentes entrevistadores possam interferir nas respostas do entrevistado e construir interpretações diversas.

A esse respeito, é importante ter clareza de que a entrevista em pesquisa qualitativa visa a compreensão parcial de uma realidade multifacetada concernente a tempo e contexto sócio-histórico específicos. Isto não significa, no entanto, defender um relativismo subjetivista, de acordo com o qual cada um tem a sua 'verdade', mas reconhecer que as visões de mundo de grupos humanos se sustentam nos níveis de compartilhamento vivenciados por eles: época, lugar, processos de socialização, nível de desenvolvimento da ciência e da sociedade, hábitos e costumes culturais, língua, ambiente etc. Diferentes entrevistadores e entrevistados podem chegar a conclusões distintas sobre um mesmo tema investigado, o que torna defensável que o pesquisador, ao relatar seus resultados, deixe bastante explícitas suas concepções e visões sobre o assunto, assim como ofereça informações detalhadas sobre os participantes da pesquisa. É isto que permitirá àquele que não participou da pesquisa refletir e criticar os resultados à luz da compreensão do contexto em que as conclusões foram extraídas.

Não se pode esquecer também que o esclarecimento dos critérios de escolha dos participantes a serem entrevistados é muito importante, visto que a aleatoriedade na abordagem qualitativa não é considerada a melhor opção. O que importa não é quantos foram entrevistados, mas se os entrevistados foram capazes de trazer conteúdos significativos para a compreensão do tema em questão.

\section{Seleção dos entrevistados: a questão da representatividade amostral}

Em pesquisas qualitativas, o fundamental é que a seleção seja feita de forma que consiga ampliar a compreensão do tema e explorar as variadas representações sobre determinado objeto de estudo. O critério mais importante a ser considerado neste processo de escolha não é numérico, já que a finalidade não é apenas quantificar opiniões e sim explorar e compreender os diferentes pontos de vista que se encontram demarcados em um contexto.

Em um ambiente social específico, o espectro de opiniões é limitado, pois a partir de um determinado número de entrevistas percebe-se o esgotamento das respostas quando elas tendem a se repetir e novas entrevistas não oferecem ganho qualitativo adicional para a compreensão do fenômeno estudado. Isto significa que já se torna possível identificar a estrutura de sentido, ou seja, as representações compartilhadas socialmente sobre determinado tema de interesse comum (Gaskell, 2002; Gondim, 2002a).

Considera-se, então, que o número de entrevistas deve ser pensado levando-se em conta os objetivos da pesquisa, os diferentes ambientes a serem considerados e, principalmente, a possibilidade de esgotamento do tema. Gaskell (2002) afirma, porém, que o número de entrevistas para cada pesquisador deve oscilar de 15 a 25 entrevistas individuais e de seis a oito no caso de entrevistas grupais, a depender do nível de aprofundamento da análise almejada e de outras decisões metodológicas do pesquisador.

A seleção dos entrevistados também deve estar relacionada à segmentação do meio social a ser pesquisado, que precisa ser pertinente ao problema da pesquisa. Os objetivos e o enfoque que se pretende dar ao tema, portanto, devem estar claros e bem definidos para que a escolha seja adequada. Um mesmo assunto pode ser de interesse de diversos grupos e pode ser compreendido de diferentes maneiras em função dos múltiplos enfoques possíveis e das características próprias de cada grupo, o que torna difícil uma única pesquisa abarcar todas as possibilidades.

Se as entrevistas são grupais, a escolha de grupos naturais pode ser uma opção ao invés de grupos compostos por amostras estatísticas. Os grupos naturais têm a vantagem de interagirem em seu cotidiano e compartilharem interesses e valores semelhan- 


\section{Márcia Tourinho Dantas Fraser}

tes. Por exemplo, podem-se entrevistar grupos rivais de adolescentes moradores de um bairro da periferia com o objetivo de investigar a violência entre jovens em centros urbanos. A intencionalidade na escolha dos grupos é importante na pesquisa qualitativa porque aproxima o pesquisador de uma realidade concreta onde ocorre o fenômeno a ser investigado.

Ainda que a entrevista seja feita com cada indivíduo em separado, a intencionalidade da escolha persiste, pois se o objetivo é conhecer com mais profundidade um tópico, é preciso que o entrevistado tenha o que falar sobre ele. É provável que qualquer cidadão tenha algo a dizer sobre os políticos, os problemas de violência e de saúde da população nas grandes cidades, mas, se o foco do estudo for sobre as conseqüências sociais da discriminação racial, a escolha dos entrevistados deve recair sobre aqueles que estão diretamente implicados.

A clareza dos caminhos que se pretende trilhar na pesquisa é fundamental neste processo. Por exemplo, se o objeto de investigação for o aborto, $o$ tema pode ser investigado a partir do ponto de vista de um grupo de advogados, que enfatizam o aspecto legal, de psicólogos, que dão destaque às repercussões psicológicas do aborto, de médicos que se preocupam em descrever os efeitos do aborto na saúde física, ou ainda de adolescentes que passaram pela experiência de um aborto.

Ao investigar a interface entre trabalho e família, no entanto, seria importante definir a amplitude do estudo, assim como as características específicas dos participantes escolhidos e as perspectivas a serem exploradas: é a perspectiva dos próprios trabalhadores que se quer abordar? É o ponto de vista do empregador que se deseja apreender? Ou o objetivo é compreender como os familiares dos trabalhadores percebem as interferências do trabalho na vida doméstica?

Para o estudo da interface entre trabalho e família, pode-se optar também por investigar o tema a partir da perspectiva de um grupo específico de profissionais. Os participantes podem ser escolhidos pelas características inerentes ao próprio tipo de trabalho, que sugiram haver dificuldades para conciliar a vida pessoal e o trabalho. É o caso de profissionais que estejam submetidos a turnos alter- nados, de executivos de grandes empresas, cujo trabalho exija viagens constantes ou mesmo mudanças freqüentes de local de moradia, ou de trabalhadores que exerçam funções de alto risco. Para a seleção dos entrevistados, portanto, vários fatores devem ser considerados conforme o enfoque dado ao tema e a abrangência pretendida no estudo.

Enfim, uma das principais finalidades da pesquisa qualitativa é a de apresentar, de forma ampla e representativa, a diversidade de pontos de vistas de um determinado grupo e, para tal, é preciso avaliar se as características de gênero, idade e instrução são relevantes e quais os benefícios de investigar alguns segmentos sociais específicos ao invés de outros. A escolha criteriosa dos participantes é fundamental para os resultados da pesquisa, na medida em que afeta a qualidade das informações obtidas e a validade da própria pesquisa (Gaskell,2002).

Os critérios de seleção nas entrevistas qualitativas se inserem no debate sobre a representatividade amostral. Minayo (1998) discute esta questão com base nas proposições de Bourdieu de que as pessoas que vivem no mesmo ambiente social tendem a desenvolver e reproduzir disposições semelhantes e, em sendo assim, os significados individuais podem estar representando significados grupais. Em outras palavras, a fala de alguns indivíduos de um grupo é representativa de grande parte dos membros deste mesmo grupo inserido em um contexto específico.

Até este ponto discorreu-se sobre a estrutura e os objetivos da entrevista, sendo discutido o papel dos participantes, os critérios de seleção dos entrevistados e a representatividade das entrevistas qualitativas. Para finalizar esta seção, serão focalizadas as entrevistas individuais e grupais.

\section{Entrevistas individuais e grupais}

As entrevistas individuais e grupais são amplamente utilizadas nas investigações científicas. Pela tradição, a pesquisa acadêmica privilegia as entrevistas individuais, ao passo que as pesquisas de mercado preferem as entrevistas em grupos. A partir da última década, entretanto, o quadro tem-se modificado com o crescimento considerável do emprego de entrevistas com grupos nas ciências sociais (Gondim, 
2002a, 2002b; Morgan, 1997).

A entrevista individual é uma interação de díade, indicada quando o objetivo da pesquisa é conhecer em profundidade os significados e a visão da pessoa. Esta modalidade de entrevista é muito utilizada em estudos de caso, história oral, histórias de vida e biografias, que demandam um nível maior de detalhamento. É preferida também quando a investigação aborda assuntos delicados, difíceis de serem tratados em situação de grupo. A escolha da modalidade individual de entrevista também pode decorrer das características ou condições do entrevistado, pois oferece mais flexibilidade para o agendamento de horário e de local de realização. É o caso de pessoas mais idosas, doentes e crianças pequenas (Gaskell, 2002).

A entrevista grupal assim como a entrevista individual pode ser estruturada, semi-estruturada ou aberta, podendo ser utilizada como única técnica de coleta de dados ou associada a outras técnicas, dependendo dos propósitos do estudo. Esta modalidade de entrevista é indicada para pesquisas cuja temática seja de interesse público ou preocupação comum, por exemplo, política, mídia, lazer, novas tecnologias, e para assuntos e questões de natureza relativamente não familiar, que não tenham o caráter excessivamente íntimo e exijam muito aprofundamento de cada pessoa.

No campo das ciências sociais essa modalidade de entrevista tem sido empregada em diversos tipos de investigações (Fontana \& Frey, 1994), tais como para construir e testar uma escala social (Bogardus, 1926), para subsidiar projetos na área de saúde (Morgan \& Spanish,1984) e para avaliar o impacto da propaganda (Merton, Fiske \& Kendall, 1990).

Uma modalidade de entrevista grupal, que éo grupo focal ou de discussão, tem apresentado um crescimento expressivo nas últimas décadas, atendendo a interesses de acadêmicos, que a usam para investigar as percepções e representações de grupos específicos, e as de profissionais que a empregam como ferramenta de gerenciamento, de tomada de decisão e de apoio a programas de intervenção (Gondim, 2002a, 2002b).

Embora alguns autores não façam claramente uma distinção entre as entrevistas grupais e grupos focais, existem diferenças fundamentais entre estas técnicas que necessitam ser destacadas, principalmente no que se refere ao papel do pesquisador, ao tipo de abordagem e aos objetivos da pesquisa.

Nas entrevistas grupais, o que se visa é conhecer as opiniões e o comportamento do indivíduo no grupo. $O$ entrevistador estabelece uma relação diádica com cada membro do grupo. Ao contrário, nos grupos focais, o que interessa são as opiniões que emergem a partir do momento em que as pessoas em grupo passam a estar sujeitas aos processos psicossociais que ocorrem neste contexto e influenciam na formação de opiniões. No grupo focal, o pesquisador tem um papel menos diretivo, ocupando o lugar de facilitador do processo de discussão grupal. Sua relação é com o grupo, pois é ele que é tomado como a unidade de análise, ao contrário da entrevista grupal em que o pesquisador se dirige a cada indivíduo e o nível de análise que adota é o do indivíduo no grupo (Gondim 2002a; Morgan, 1997).

A escolha entre entrevistas individuais, grupais e grupos focais é fundamental para os rumos da investigação, uma vez que esta decisão orienta a maneira como os dados serão coletados e analisados.

Morgan (1997) compara as entrevistas individuais e as entrevistas grupais, ao apresentar algumas de suas vantagens e desvantagens. Nas entrevistas grupais, o autor supracitado afirma que a técnica oferece ao pesquisador a oportunidade de observar in loco as semelhanças e diferenças entre opiniões e experiências dos participantes. Nas entrevistas individuais este mapeamento só poderia ser obtido pela posterior análise comparativa de cada uma das entrevistas transcritas. A entrevista individual, a seu modo, é vantajosa quando o que está em jogo é o conhecimento em profundidade dos significados pessoais de cada participante. Favorece também a maior proximidade de cada participante individualmente e, em conseqüência, permite maior controle do investigador da própria situação da entrevista, visto que, na situação de grupo, o risco de se desviar do tema é maior.

Em síntese, as entrevistas grupais e, mais especificamente os grupos focais permitem ampliar a compreensão transversal de um tema, ou seja, mapear os argumentos e contra-argumentos em relação a um tópico específico, que emergem do contexto do pro- 


\section{Márcia Tourinho Dantas Fraser}

cesso de interação grupal em um determinado tempo e lugar (jogo de influências mútuas no interior do grupo), enquanto as entrevistas individuais permitem ampliar a compreensão de um tópico específico de modo aprofundado para uma mesma pessoa, em seu processo de interação diádica com o entrevistador.

\section{Considerações finais}

Este artigo teve o propósito de abordar as entrevistas como técnica de pesquisa na abordagem qualitativa. As entrevistas ocupam um lugar de destaque no rol das técnicas de pesquisa em ciências sociais, principalmente por lidar com a palavra, veículo privilegiado da comunicação humana. Por meio da interação verbal de entrevistado e entrevistador, é possível apreender significados, valores e opiniões e compreender a realidade social com uma profundidade dificilmente alcançada por outras técnicas, como questionários e entrevistas estruturadas. Isto porque, no caso das entrevistas qualitativas, a relação estabelecida entre o entrevistador e o entrevistado permite um diálogo amplo e aberto favorecendo não apenas o acesso às opiniões e às percepções dos entrevistados a respeito de um tema, como também a compreensão das motivações e dos valores que dão suporte à visão particular da pessoa em relação às questões propostas.

Ressalta-se, entretanto, em concordância com o que diz Silverman (2000) que, embora as entrevistas sejam uma alternativa inegável para pesquisas cujo objetivo é apreender como as pessoas "vêem as coisas”, existem outras técnicas mais adequadas quando o foco da pesquisa é conhecer como as pessoas "fazem as coisas”, como, por exemplo, a observação participante e sistemática.

Na primeira seção, procurou-se caracterizar sucintamente a abordagem qualitativa de pesquisa apresentando as principais diferenças entre esta abordagem metacientífica e a quantitativa ou monotética. Considerou-se importante fazer este percurso porque as entrevistas são utilizadas por ambas as abordagens e essas diferenças repercutem no manejo da própria técnica, como por exemplo, na estruturação de um roteiro, no papel do entrevistador e do entrevistado e na análise dos resultados.

As entrevistas qualitativas são largamente em- pregadas na pesquisa social, podendo ser de vários tipos e responder a objetivos diversos. Uma de suas finalidades é a de compreender um contexto particular, assim como a de ajudar na construção de modelos teóricos.

A relação intersubjetiva do entrevistador e do entrevistado é vista como uma característica central da entrevista qualitativa, por permitir a negociação de visões da realidade resultantes da dinâmica social onde os participantes constroem conhecimento e procuram dar sentido ao mundo que os cerca (AlvesMazzotti \& Gewandsznajder, 1994; Fontana \& Frey, 2000; Minayo, 1998).

Como toda técnica de pesquisa, as entrevistas apresentam limites. Alguns são característicos da própria interação social que tem seu curso nas entrevistas, outros são mais específicos da modalidade de entrevista grupal ou individual.

Enfim, todo e qualquer método deve procurar dar respostas (positivas ou negativas) a pelo menos quatro exigências científicas: validade constructo, validade externa, validade interna e confiabilidade (Yin, 2001). A validade de constructo demanda que o pesquisador reconheça que a técnica de entrevista seja a melhor forma de abordar (ou mensurar) o seu objeto de estudo; a validade externa diz respeito ao poder de generalização, que, no caso da pesquisa qualitativa, é limitado ao contexto de estudo; a validade interna se refere à consistência dos procedimentos internos de pesquisa, que, no caso da pesquisa qualitativa, e da entrevista pode ser obtida pela construção de modelo teórico que expressa a estrutura de sentido dos significados declarados pelos participantes; e a confiabilidade, que se refere à capacidade de uma pesquisa repetir os mesmos procedimentos e apresentar os mesmos resultados. Neste último caso, a pesquisa qualitativa leva desvantagem em relação à pesquisa experimental e quantitativa, a não ser que conceba que a confiabilidade pode vir a ser obtida caso o modelo teórico construído a partir dos resultados do contexto específico possam vir a ser pertinentes a outros contextos similares (Alves-Mazzotti \& Gewandsznajder 1994).

Outras alternativas de obter confiabilidade são as avaliações críticas dos participantes e de outros pesquisadores. A primeira consiste em averiguar se as interpretações do pesquisador fazem sentido para 
o próprio participante, o que pode ser feito, inclusive, no momento da entrevista, por meio de perguntas que permitam ao entrevistador esclarecer pontos obscuros e entender mais claramente o que dizem os entrevistados (texto negociado). O questionamento dos pares, a segunda alternativa de confiabilidade, consiste em submeter os resultados à avaliação de outros colegas pesquisadores para que sejam apontados e discutidos as falhas de procedimentos e os equívocos de interpretação.

Para finalizar, qualquer que seja a técnica ou o método escolhido pelo pesquisador haverá limitações. Aliás, a própria escolha do objeto de estudo de pesquisa já requer um recorte da realidade a ser investigada. O importante é que tal escolha esteja cada vez mais respaldada em claras concepções do pesquisador sobre a natureza do objeto de estudo e o nível de análise e de descrição pretendidos.

\section{Referências Bibliográficas}

Alves-Mazzotti, A.J. \& Gewandsznajder (1994). Paradigmas qualitativos. Em R. Bogdan \& S.K.Biklen (org.), Investigação qualitativa em educação: Uma introdução a teoria e aos métodos (pp.130-176 ). Porto, Portugal: Porto Editora.

Amaral, M.C.P. (1987). Dilthey: Um conceito de vida e uma pedagogia. São Paulo: EDUSP.

Bardin, L. (1977). Análise de conteúdo. Lisboa: Edições 70

Bartholomew, K., Henderson, A.J.Z. \& Márcia, J.E. (2000). Coding semistructured interviews in social psychology research. Em H.T. Reis \& C.M. Judd (orgs.), Handbook of research methods in social and personality psychology (pp.286-312). UK: Cambridge University Press.

Bogardus, E.S. (1926). The group interview. Journal of Applied Sociolog, 10, 372-382.

Darley, J.M. \& Gross, P.H. (2000). A hypothesisconfirming bias in labeling effects. Em C. Stangor (org.), Stereotypes and prejudice (pp. 212- 225). Philadelphia: Psychology Press.

Flick, U. (2002). Entrevista episódica. Em M.W.
Bauer \& G. Gaskell. (orgs.), Pesquisa qualitativa com texto, imagem e som. Um manual prático (pp. 114-126). Petrópolis: Vozes.

Fontana, A. \& Frey, J.H. (1994). Interviewing the art of Science. Em N. Denzin \& Y.S. Lincoln (orgs.), Handbook of qualitative research (pp.361-376). London: Sage Publications Inc.

Fontana, A. \& Frey, J.H. (2000). The Interview: from structured questions to negotiated text. Em N. Denzin \& Y.S. Lincoln (orgs.), Handbook of qualitative research (pp. 645-672). London: Sage Publications Inc.

Gaskell, G. (2002). Entrevistas individuais e de grupos. Em M.W. Bauer \& G. Gaskell (orgs.), Pesquisa qualitativa com texto, imagem, e som. Um manual prático (pp.64-89). Petrópolis: Vozes.

Gergen, M. \& Gergen, K (2000). Qualitative inquiry: Tensions and transformations. Em N. Denzin \& Y.S. Lincoln (orgs.), Handbook of qualitative research (pp. 1025-1046). London: Sage Publications Inc.

Gondim, S.M. (2002a). Grupos focais como técnica de investigação qualitativa: Desafios metodológicos. Paidéia. Cadernos de Psicologia e Educação, 12(24), 149-161.

Gondim, S.M. (2002b). Perfil profissional e mercado de trabalho: relação com a formação acadêmica pela perspectiva de estudantes universitários. Estudos de Psicologia,7(2), 299-308.

Haguette, T.M.F. (2001). Metodologias qualitativas na sociologia. Petrópolis: Vozes.

Hollis, M. (2002). Filosofia das ciências sociais. Em N. Bunnin \& E.P. Tsui-James (orgs.), Compêndio de filosofia (pp. 357-387). São Paulo: Edições Loyola.

Jovchelovitch, S \& Bauer, M.W. (2002). Entrevista narrativa. Em M.W. Bauer \& G. Gaskell (orgs.), Pesquisa qualitativa com texto, imagem, e som. Um manual prático (pp.90-113). Petrópolis: Vozes.

Kemmis, S. \& Mctaggart, R. (2000). Participatory action research. Em N. Denzin \& Y.S. Lincoln 
152 Márcia Tourinho Dantas Fraser

(orgs.), Handbook of qualitative research (pp. 567-606). London: Sage Publications Inc.

Khun, T. (1975) A estrutura das revoluções científicas. São Paulo: Perspectiva

Lincoln,Y.S. \& Guba, E.G. (2000). Paradgmatic controversis, contradictions, and confluences. Em N. Denzin \& Y.S. Lincoln (orgs.), Handbook of qualitative research (pp. 163-188). London: Sage Publications Inc.

Lodi, J.B. (1991). A entrevista: teoria e prática. São Paulo: Pioneira.

Masterman, M. (1979). A natureza de um paradigma. Em I. Lakatos \& A. Musgrave (orgs), A crítica e o desenvolvimento do conhecimento (pp. 72108). São Paulo: Cultrix, Edusp.

Merton, R.K., Fiske, M. \& Kendall, P.L. (1990). The focused interview. A manual of problems and procedures. New York: The Free Press.

Minayo, M.C. de S. (1998). O desafio do conhecimento: Pesquisa Qualitativa em Saúde. São Paulo: HUCITEC; Rio de Janeiro: ABRASCO.

Minayo, M.C. de S., Deslandes, S.F.; Neto, O.C. \& Gomes, R. (2000). Pesquisa social teoria método e criatividade. Petrópolis: Vozes.

Morgan, D. (1997). Focus group as qualitative research. London: Sage Publications.

Morgan, D. \& Spanish (1984). Focus Group: A new tool for qualitative research. Qualitative Sociology, 7, 253- 270.

Radnitzky, G. (1970). Escolas contemporâneas de metaciência. Gottenburgo: Scandinavian Univ. Books.

Rey, G. (2002) Pesquisa qualitativa em psicologia. Caminhos e desafios. São Paulo: Thomson Pioneira.

Schütz, A. (1972). Fenomenologia del mundo social. Buenos Aires: Editorial Paidos.

Silverman, D. (2000). Analysis talk and text. . Em N. Denzin \& Y.S. Lincoln (orgs.), Handbook of qualitative research (pp. 821-834). London: Sage Publications Inc.
Smith, C. (2000). Content analysis and narrative analysis. Em H.T. Reis, \& C.M. Judd (org.), Handbook of research methods in social and personality psychology (pp.313-38). UK: Cambridge University Press.

Smith, J.A., Harré, R. \& Langenhove, L.V. (1995). Rethinking psychology. London: Sage Publications

Yin, R.K. (2001). Estudo de caso. Planejamento e método. Porto Alegre: Bookman. 